
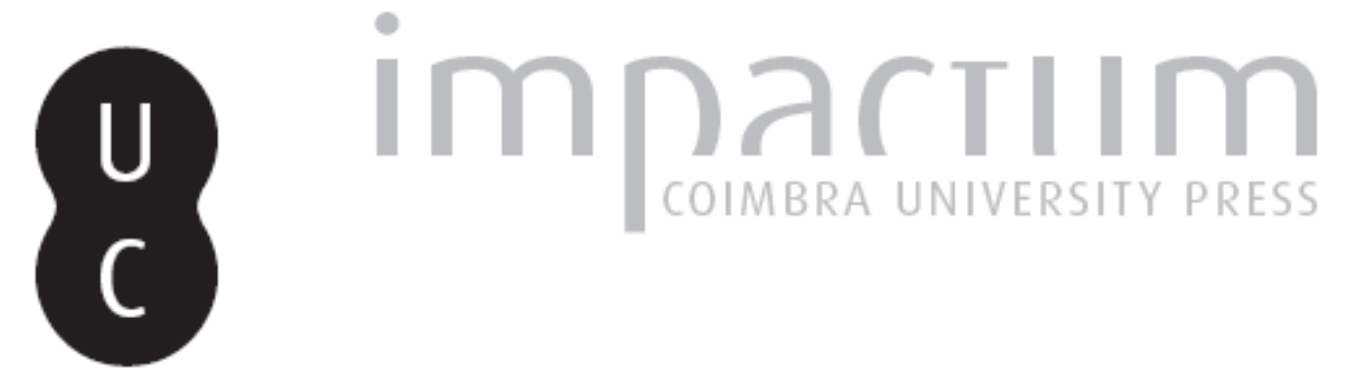

\title{
Nascer duas vezes: vicissitudes da lírica italiana dos primeiros séculos
}

Autor(es): Santagata, Marco

Publicado por: Imprensa da Universidade de Coimbra

URL persistente:

URI:http://hdl.handle.net/10316.2/42674

DOI:

DOI:https://doi.org/10.14195/0870-8584_1_1

Accessed : $\quad$ 26-Apr-2023 13:00:56

A navegação consulta e descarregamento dos títulos inseridos nas Bibliotecas Digitais UC Digitalis, UC Pombalina e UC Impactum, pressupõem a aceitação plena e sem reservas dos Termos e Condições de Uso destas Bibliotecas Digitais, disponíveis em https://digitalis.uc.pt/pt-pt/termos.

Conforme exposto nos referidos Termos e Condições de Uso, o descarregamento de títulos de acesso restrito requer uma licença válida de autorização devendo o utilizador aceder ao(s) documento(s) a partir de um endereço de IP da instituição detentora da supramencionada licença.

Ao utilizador é apenas permitido o descarregamento para uso pessoal, pelo que o emprego do(s) título(s) descarregado(s) para outro fim, designadamente comercial, carece de autorização do respetivo autor ou editor da obra.

Na medida em que todas as obras da UC Digitalis se encontram protegidas pelo Código do Direito de Autor e Direitos Conexos e demais legislação aplicável, toda a cópia, parcial ou total, deste documento, nos casos em que é legalmente admitida, deverá conter ou fazer-se acompanhar por este aviso.

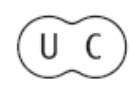




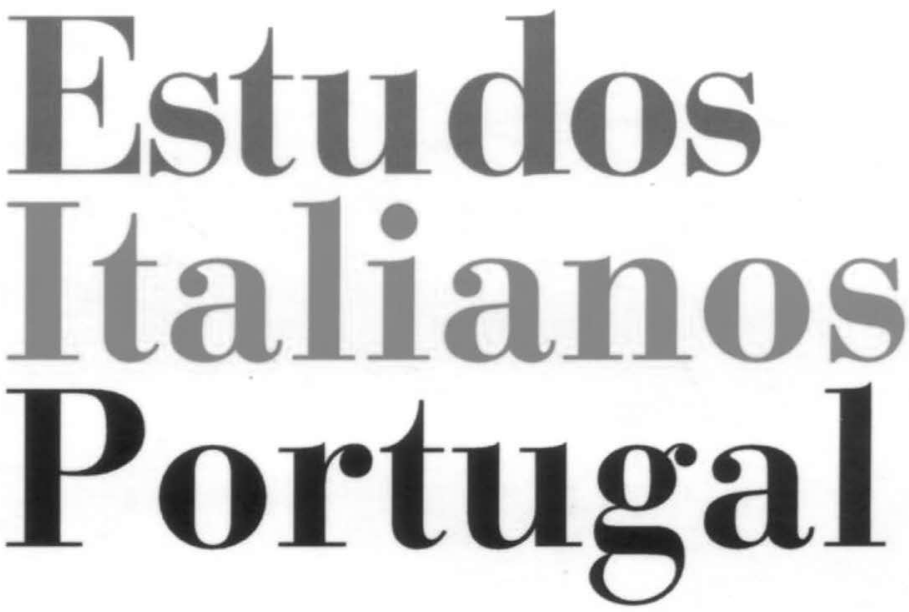

Instituto

Italiano

de Cultura

em Portugal

Nova Série

$\mathbf{N}^{\circ} \mathbf{1}$

2006 
NASCER DUAS VEZES. VICISSITUDES DA LÍRICA ITALIANA DOS PRIMEIROS SÉCULOS ${ }^{\star}$

Marco Santagata

1. As obras de GRANDE DIVUlGaÇÃo, e mesmo declaradamente 'científicas', desenham frequentemente uma história da lírica italiana dos séculos XIII e XIV muito, para não dizer demasiado, simplificada. No fundo, delineiam uma cadeia principal constituída por poucos elos (Sicilianos, Stilnovo com Guinizzelli, Dante e Petrarca), ladeada, em contracanto, pelo fio dos jocosos ou realistas.

Tomemos como ponto de referência duas obras significativas, publicadas a quarenta anos de distância uma da outra: os clássicos Poeti del Duecento de Contini, editados em 1960, e a Antologia della poesia italiana organizada por Segre e Ossola, cujo primeiro volume, dedicado ao século XIII, remonta a $1997^{1}$

A antologia de Contini, mais do que um cânone, fixou uma imagem da poesia do século XIII, aquela que cada um de nós tem ainda hoje à frente dos olhos, quando pensa na poesia dessa centúria, tomada no seu conjunto. O século XIII de Contini, longe de se esgotar nas abstractas finezas do código cortês ou nas paralelas abstrusidades retóricas do trobar

* Tradução de Rita Marnoto.

1 Poeti del Duecento, a c. di Gianfranco Contini, Milano-Napoli, Ricciardi 1960, 2 vol.; Antologia della poesia italiana, diretta da Cesare Segre e Carlo Ossola, Duecento, Torino, Einaudi 1997 (1999). 
clus, afinal produtos fortemente codificados, é percorrido por tensões expressionísticas, por desígnios experimentalistas, por uma pluralidade de propostas literárias que pressupõe uma pluralidade de utentes. Mas dessa imagem de conjunto a lírica é tão só uma parte.

Também em âmbito lírico Contini introduz inovações orientadas no sentido da variedade. Se, dez anos antes, Salinari tinha articulado a sua antologia de Poesia lirica del Duecento $^{2}$ apenas em três partes, "I Siciliani", "Guittone e i guittoniani", "Gli Stilnovisti" (sem Dante), Contini (que afirma, contudo, na nota de apresentação, ter adoptado o esquema historiográfico "più accettato, frusto e pacifico") subdivide a lírica profana em numerosos capítulos: "Scuola siciliana", "Poesia cortese toscana e settentrionale", "Poesia 'popolare' e giullaresca" ("popolare" entre aspas, "al perento modo romantico"), "Poesia 'realistica' toscana" (também entre aspas), "Dolce Stil Novo" (sem Dante, mas com Guinizzelli), "Vicini degli stilnovisti". Contudo, fica a impressão de que, para a lírica, Contini está menos determinado em se afastar dos códigos aceites. Se considerarmos a percentagem de textos antologizados (calculada com base no conjunto dos líricos, cerca de 500), a sua progressão (Sicilianos 12\%, Corteses 25\%, Stilnovistas 33\%) não se afasta muito da de Salinari (Sicilianos 17\%, Guittone e guittonianos 37\%, Stilnovistas 45\%).

Mais alguns números. Nos Poeti de Contini, os Sicilianos e os Silnovistas (sem Dante) juntos valem 46\%; com o acrescento dos "Vicini degli stilnovisti", chegam a 60\%. Uma presença estável no cânone é a dos poetas "realistas": somando-os aos precedentes, a percentagem global chega a 73\%. Quarenta anos volvidos, a antologia de Segre e Ossola mantém, substancialmente, a mesma planificação: neste caso, a "Scuola siciliana" vale 19\%, os "Siculo-toscani" 21\%, o

2 La poesia lirica del Duecento, a c. di Carlo Salinari, Torino, Utet 1951.
"Stilnovo" 28\%. Crescem os "realistas" (etiquetados como "Poeti giocosi"), com 28\%. Como se vê, a parelha Sicilianos - Stilnovistas (sem Dante), por si só, atesta 47\% (eram 46\% em Contini). Com o acrescento dos jocosos, a percentagem sobe para $71 \%$, muito próxima, pois, dos $73 \%$ de Contini. Já observei que destas antologias anda ausente o Dante lírico. É evidente que com a sua presença se faria ainda mais nítida a linha que identifica o eixo de suporte da lírica do século XIII na sucessão Sicilianos - Stilnovo, com um parênteses cortês e o apêndice cómico-realista.

Fora de Itália, esta representação faz-se ainda mais acentuada, para não dizer esquemática. Esquemática é a das Epochen der italienische Lyrik (1964) de Hugo Friedrich ${ }^{3}$ : a um primeiro capítulo somatório (trovadores provençais, sicilianos, poesia religiosa e burlesca), seguem-se os capítulos dedicados ao "Dolce stil novo", a Dante e, sem solução de continuidade (facto a ter presente), a Petrarca. Mais articulado é o quadro oferecido pela Anthologie bilingue de la poésie italienne publicada pela Pléiade em $1994^{4}$. Articulado, mas considerando à parte a dilatação do número de textos jocosos e realistas, na linha de quanto já observámos: $23 \%$ de textos sicilianos, $12 \%$ de sículo-toscanos, 35\% de jocosos, $29 \%$ de stilnovistas (sem Dante). Como em Friedrich, também neste caso o capítulo dantesco é imediatamente seguido pelo petrarquesco.

O percurso delineado é discutível, não por sacrificar sabe-se lá que obra-prima, ou por mortificar sabe-se lá que grande poeta, mas por insinuar uma ideia evolutiva da nossa lírica das origens que acaba por se projectar bem para além dos

\footnotetext{
3 Trad. it.: Hugo Friedrich, Epoche della lirica italiana, Milano, Mursia 1974 $-76,3$ vol.

${ }^{4}$ Anthologie bilingue de la poésie italienne, Préface par Danielle Boillet et Marziano Guglielminetti, Edition établie sous la direction de Danielle Boillet, avec la collaboration de Giovanni Clerico, José Guidi, Maurice Javion, François Livi, Laura Nay, Claude Perrus et André Rochon, Paris, Gallimard 1994.
} 
confins do século XIII. É a ideia de um curso linear e pacífico, de uma homogeneidade que unifica séculos de poesia lírica italiana. Era o que escrevia Friedrich em 1964: a lírica italiana "ha, rispetto a quella francese, spagnola, inglese e tedesca, il vantaggio di una maggiore coerenza. Essa non presenta brusche fratture di tradizione. A parte alcuni mutamenti tematici, resta per secoli vivo quel patrimonio fondamentale di vocaboli, di forme linguistiche, di significati, di mezzi stilistici, di generi che fu fondato dai siciliani e dai fiorentini del XIII secolo e ratificato dal Petrarca" ${ }^{5}$. Repete-o Segre em 1997: "Si può dire che la nostra poesia lirica, compreso il suo bifrontismo, segue un percorso molto lineare, così che per l'ethos, non meno che per lessemi e sintagmi, per topoi ecc., si può tracciare facilmente una storia, che culminerà con Petrarca per poi seguire il suo modello sino al Seicento"6.

Parece-me, pelo contrário, que essa história foi bem mais fracturada e dramática, mais rica de potencialidades não expressas e de motivações silenciadas, e menos sujeita à ditadura de uns poucos ou, melhor dizendo, sujeita à ditadura de poucos em virtude de razões a serem procuradas mais fora da instituição literária, do que na aparente continuidade de topoi e linguagens. E parece-me que os fios se embaraçam logo a partir do século XIII.

2. É bem certo que, se privilegiarmos os extremos, ou seja, por um lado, aquela estranha experiência de lírica cortês sem corte que foi a poesia imperial da Sicília, por outro lado, aquela estranha tentativa de lírica aristocrático-burguesa que foi o Stilnovo, e se pusermos em relevo os factores de continuidade, então o emaranhado de fios que enreda o século XIII desfaz-se de forma simples e linear. Não é, pelo contrário, assim, se tivermos em linha de conta os impulsos

${ }^{5}$ Epoche della lirica italiana, pp. V-VI

${ }_{6}$ Antologia della poesia italiana, p. XVIII. centrífugos e as tensões que percorrem a lírica desse século. Nesse caso, emergirão fracturas profundas, bem mais profundas do que o bifrontismo a que acenava Segre com o convívio, no último quarto de século, de uma lírica áulica e de outra cómico-realista. De resto, observo à parte, o termo bifrontismo, já usado por Contini, talvez nem sequer confira plena razão de ser a essa dualidade específica. Na verdade, designa duas faces de uma realidade que deve ser lida de forma unitária. Hoje, contrariando a tendência de origem idealista que leva a ver os jocosos como um fenómeno prevalentemente metaliterário, de consciente paródia do contemporâneo registo trágico, começa a despontar a tendência, em parte antecipada pelos positivistas, para considerar esse filão poético na sua autonomia, desvinculando-o da ideia de contracanto paródico, para restituir dignidade de vivido aos conteúdos que exprime . $^{7}$.

As fracturas a que anteriormente aludia são, porém, outras.

Primeira de todas, a linguística. O facto de, em Itália, a lírica ser bilingue - toscana (como os Sicilianos adquirem verdadeira importância depois de "traduzidos", acabam, também eles, por fazerem parte do panorama lírico em toscano) e provençal - não tem merecido, nas reconstruções historiográficas, todo o relevo que merece. A diversidade da especialização de filólogos românicos e de filólogos italianos parece-me ter constituído obstáculo a uma compreensão global da lírica em vulgar. Apesar de não faltarem poetas que escrevem em ambas as línguas, mais do que de bilinguismo dever-se-á falar de duplo circuito: provençal, a norte dos Apeninos; toscano, na Itália central (com os seus anexos bolonheses). O duplo circuito diferencia-se claramente, pelo que diz respeito às pessoas fisicas, os poetas, mas muito menos pelo que diz respeito à circulação de livros. Quero dizer

Cf. o cap. "La tradizione comico-realistica" de Claudio Giunta, Versi a un destinatario. Saggio sulla poesia italiana del Medioevo, Bologna, Il Mulino 2002. 
que, se os trovadores viveram sobretudo nas grandes cortes feudais, os cancioneiros provençais devem ter tido leitores não só na corte de Frederico II, mas também nas cidades toscanas. Da coexistência entre separação e intersecção, as histórias da literatura, e as antologias ainda mais, não oferecem uma representação adequada. Quem quiser ter uma primeira ideia, mesmo só no plano visual, do panorama lírico italiano de meados do século, deve folhear as páginas dos cancioneiros antigos editados por Avalle ${ }^{8}$ e também as do último volume de Los trovadores de Martin de Riquer ${ }^{9}$, onde são antologizados os trovadores italianos activos em Itália no século XIII.

O duplo circuito linguístico deve ser colocado em relação, pelo menos, com dois outros fenómenos: com o atraso da lírica num vulgar italiano em relação ao resto da Europa e com a concentração da lírica em toscano numa área geográfica restrita. Bilinguismo, atraso e concentração geográfica denunciam o facto de em Itália a produção lírica andar imiscuída no grande confronto político-social e conotam, como sendo de classe, não só a produção em provençal das cortes feudais, mas também a produção em toscano das comunas centro-italianas. Seria dificil, para além de impróprio, tentar dar uma definição dessa classe em termos modernos, apesar de nos entendermos se dissermos que os líricos que escrevem em toscano são expoentes cultos do mundo urbano ligado ao comércio, às manufacturas e à finança. A novidade e a peculiaridade da situação italiana residem no facto de, neste caso, a lírica num vulgar local se ter quase de repente libertado do mundo das cortes feudais. O que significa que, para a lírica toscana, tendo em linha de conta a instituição

8 Concordanze della lingua poetica italiana delle Origini (CLPIO), a c. di D'Arco Silvio Avalle e con il concorso dell'Accademia della Crusca, Milano-Napoli, Ricciardi 1992.

9 Martín de Riquer, Los trovadores. Historia literaria y textos, Tomo III, Barcelona, Ariel 1983 (1975). literária, podemos falar de uma tradição cortês, mas, considerando o papel que essa tradição desempenhava na sociedade feudal, não podemos falar de uma lírica funcionalmente cortês. Inútil sublinhar quanto uma "cortesia" citadina e mercantil possa ser diferente, nas suas finalidades essenciais, daquela que, durante séculos, foi fundamento e base ideológica da sociedade nobiliária ${ }^{10}$. Digamos, com palavras breves, que se a velha cortesia era instrumento de integração e coesão de uma classe dirigente estabelecida, a nova cortesia é um dos canais para a formação de uma classe dirigente in fieri.

O mundo comunal é vário, com divisões e querelas, é social e culturalmente estratificado, está aberto ao novo e, ao mesmo tempo, está disponível para absorver estilos de vida e tipos de consumo cultural de marca nobiliárquica. A lírica exprime tudo isso: é vária quanto ao conteúdo e à forma, encontra-se dividida em escolas e correntes, anda envolvida em diatribes ideológicas e políticas, sempre pronta para absorver a tradição e, da mesma feita, para a contestar, é conservadora e experimental até à provocação, tanto se pode dirigir com uma linguagem críptica a grupos de iniciados, como dar voz a experiências da vida quotidiana ou falar à nova aristocracia com a linguagem da velha e às camadas populares com linguagens destruturadas. Em suma, a lírica da "geração do meio" não pode ser circunscrita aos confins das maneiras formalizadas, das escolas e dos códigos fechados. É como se a homogeneidade um pouco artificial dos Sicilianos, depois de o terreno toscano ter sido fertilizado, se desfizesse em pedaços. Da sua explosão, a par do persistente e dominante filão amoroso, nasceram poesia política, poesia partidária, poesia moral, poesia doutrinal, científica, didáctica, poesia goliarda e jocosa. Até poesia pré-artís-

10 Aludo à interpretação geral da lírica trovadoresca de Erich Köler, Sociologia della Fin'amor. Saggi trovadorici, Traduzione e introduzione di Mario Mancini, Padova, Liviana 1976. 
tica nasceu. Dos cancioneiros Laurenziano, Palatino e Vaticano, Avalle extraiu uma série de textos predantescos nos quais (são palavras suas) "si affollano personaggi incredibili [...], carcerati e usurai, indovini e cartomanti, alchimisti e teologi rissosi, buffoni e falliti". "L'interessante (continua Avalle) è che non si tratta di poesie manieristiche, ma di testimonianze [...] di esperienze vissute in proprio"; "la più parte [di questi poeti] sembra [...] gente venuta dal nulla (letterario)" "11. Em conclusão, é o resto dos sobreviventes de um universo de poesia pré-artística que foi varrido pelo curso da história ${ }^{12}$.

Não se pense que no sector que é, de longe, o mais importante, o lírico-amoroso, reine paz e concórdia. E como poderia reinar se, por exemplo, a dicotomia entre trobar leu e trobar clus tantas vezes supera o plano da retórica, chegando até a deixar entrever os contornos de uma divisão política: guibelinos e filo-imperiais, os 'corteses' do estilo chão; guelfos, os guitonianos do estilo obscuro? De resto, a oposição entre corteses e anticorteses fica muito para além da disputa teórica de amore ou da pura altercação poética: entre os que repisam os velhos temas da fin'amor e as guinadas contra o amor adúltero dos Guittone, dos Monte Andrea, dos Chiaro Davanzati, vai uma diferença ideológica profunda, uma linha de demarcação que distingue dois modos de conceber a família e a estrutura social citadina ${ }^{13}$.

11 Concordanze della lingua poetica italiana delle Origini, p. 840.

12 Outras importantes considerações sobre o "realismo", entre aspas, da lírica do século XIII, encontram-se no livro de Claudio Giunta, Versi a un destinatario.

13 Antecipei algumas linhas da minha interpretação da lírica do século XIII na comunicação, La fondazione del canone e della biblioteca volgare, apresentada ao congresso da "Associazione degli Italianisti Italiani” realizado em Roma em 2001 (Il Canone e la Biblioteca. Costruzioni e decostruzioni della tradizione letteraria italiana, a c. di Amedeo Quondam, Roma, Bulzoni 2002, pp. 3-21), também publicada, com variantes, na "Nuova Rivista di Letteratura italiana”, IV (2001), pp. 9-39.
Estas sumárias observações queriam sugerir a ideia de que a lírica toscana da "geração do meio", que nós hoje lemos como género literário especializado e para especialistas, então, no ponto máximo do crescimento económico e social dos novos estratos citadinos e antes de a Commedia de Dante ter descompaginado tudo, se apresentou como sendo o instrumento literário, senão exclusivo, certamente mais dúctil e potente, que foi elaborado para falar da realidade: amorosa, política, ideológica, existencial, criatural. É este o quadro sobre o qual se devem projectar as recusas, as polémicas, a orgulhosa diversidade daquele punhado de líricos florentinos que Dante há-de etiquetar como cultores do "dolce stil novo".

São poucos, de facto, mas agressivos. Sobretudo, são lúcidos e determinados quando avançam com um programa poético que, sem que o pareça, se tinge de fortes tons ideológicos. Arrisco uma afirmação que poderá parecer um pouco paradoxal: a sua, é a única verdadeira tentativa de criar uma lírica funcionalmente cortês. $\mathrm{O}$ que a experiência tem de extraordinário reside no facto de ter sido feita no coração de uma Florença guelfa, mercantil e financeira. A sua corte é ideal e metafórica, tal como de certa forma o será a "aula" imperial dantesca: o lugar virtual onde aristocracia social e aristocracia de cultura se podem encontrar até coincidirem. Para Guido, Dante e os seus amigos, parece ser claro que uma poesia rigorosamente amorosa pelos temas tratados, leu na forma e lógico-filosófica nos seus fundamentos, não é um regresso ao passado, mas o modo de enlaçar, a uma tradição 'alta', uma jovem aristocracia intelectual que se propõe como vanguarda dos novos estratos sociais. Quanto mais o seu código poético se afasta de compromissos com a realidade, tanto mais os seus textos se enchem de reais valências ideológicas. Poucas vezes, em meu entender, uma tão patente abstracção de resultados se radicou no próprio dinamismo das transformações sociais. 
3. Aquela estação, com a sua lírica multiforme, experimental, envolvida numa realidade e em lutas políticas, sociais e ideológicas, que tinha podido marcar de modo duradouro o curso da nossa poesia, revelou-se uma potencialidade não expressa. A lírica italiana seguiu outras estradas, privilegiou o tema amoroso e a estabilidade dos estatutos formais de matriz stilnovista-petrarquesca.

Foi, na verdade, a chamada à ordem ${ }^{14}$, primeiro, dos Stilnovistas, depois, de Petrarca, a sufocar os possíveis desenvolvimentos heterodoxos da lírica do século XIII? Se observarmos a história literária de cima, não podemos deixar de responder afirmativamente. Mas, para se apresentar assim, o ponto de observação deve ser colocado suficientemente alto, de modo a anular o lapso cronológico de mais de um século: tanto é o tempo que passa, na verdade, até que em Itália se forme e se consolide uma tradição lírica dotada daquelas características de repetibilidade, ordem e delimitação temática que se podem resumir com o nome de petrarquismo. É, pois, evidente que a linha historiográfica escolar, e não só escolar, Stilnovismo - Petrarca - petrarquismo, introduz simplificações e distorções que não têm correspondente na história de outros géneros literários.

Os Stilnovistas tiveram sucesso, sobretudo em Florença, e foi sobretudo em Florença que o continuaram a ter nas décadas subsequentes. Honestamente, não se pode afirmar que tenham modelado a lírica do século XIV. Também Petrarca teve sucesso, mas para poucos. Também no seu caso, não se pode propriamente dizer que tenha tido peso na lírica do seu século. De resto (e tive ocasião de o notar muitas vezes ${ }^{15}$ ), vinha de um outro mundo, de um outro mundo

14 Segundo a célebre definição de Gianfranco Folena, Cultura e poesia dei Siciliani, in Storia della Letteratura Italiana, I. Le origini e il Duecento, Milano, Garzanti 1965, p. 290.

15 Remeto para Marco Santagata, I frammenti dell'anima. Storia e racconto nel Canzoniere di Petrarca, Bologna, Il Mulino 2004 (II ed.) e para a Introduzione a geográfico e cultural, e além disso nas suas rima falava para pessoas bem diferentes dos pobres (culturalmente pobres) versejadores da sua época. É um dado de facto que nas recolhas miscelâneas do século XIV e de inícios do século XV, ou seja, manuscritos que fotografam o quadro do que efectivamente se lia, aparecem os nomes de Cavalcanti, Guinizzelli, Dante, mas aparecem menos do que os de outros rimadores do século XIV que hoje são, para nós, semidesconhecidos. Além disso, o nome do velho Guittone ainda não tinha sido esquecido. Um outro dado de facto é o de que até o nome de Petrarca também só esporadicamente se encontra. Mais do que de nomes, trata-se de textos. Na maior parte dos casos, as composições são anónimas e o anonimato atinge do mesmo modo grandes e pequenos ${ }^{16}$. Para um leitor médio de poesia, nas primeiras décadas do século XV, os grandes autores não coincidem com os de hoje: são os Antonio da Ferrara, os Fazio degli Uberti, os Francesco da Vannozzo, os Simoni Serdini. Se tivéssemos de indicar o big, a escolha não poderia incidir senão sobre um: Simone Serdini da Siena, chamado "il Saviozzo".

Nenhum dos rimadores que acabaram de ser nomeados se distingue pelas suas qualidades poéticas. Os líricos do século XIV, no seu conjunto, são pobres de valor, mas em grande número. Relativamente ao século precedente, deu-se um salto quantitativo. Seria necessário muito tempo para traçar um desenho fidedigno da poesia do século XIV: é demasiado vária (nos temas, nos géneros e nas formas) para poder ser arrumada com meia dúzia de palavras. Contudo,

Francesco Petrarca, Canzoniere, ed. commentata a c. di Marco Santagata, Nuova edizione aggiornata, Milano, Mondadori 2004.

${ }^{16}$ Um código representativo dessa realidade é o ms. da Laurenziana, "Conventi soppressi 122", acerca do qual se pode considerar a tese de doutoramento, discutida na Universidade de Pisa em 2004, de Maria Clotilde Camboni (Un manoscritto miscellaneo di rime e prose volgari: Firenze, Biblioteca Medicea Laurenziana, Conventi soppressi 122). 
para nossa sorte, a impossibilidade de a reduzir a um punhado de categorias bem definidas é facto por si muito significativo: a resistência às classificações é índice de uma substancial continuidade entre a variedade prestilnovista e aquele engarrafamento tipológico do século XIV. As potencialidades polifónicas da poesia lírica da "geração do meio" não só superaram as barreiras que os Stilnovistas tinham pretendido erigir, mas acentuaram-nas ainda mais, para não dizer que levaram a uma deflagração. Bastará, porém, uma simples leitura, para colher uma diferença substancial entre a polifonia do século XIII e a anarquia do século sucessivo. Se um texto amoroso, político, moral ou realista do século XIII transmite ao leitor uma sensação de 'veracidade' e de 'autenticidade', um texto amoroso, moral, político ou realista de um dos tantos rimadores do século XIV (não sendo Petrarca, bem entendido) não consegue ser levado mesmo a sério. Ou seja, não consegue dissipar a sensação de que se trata de um objecto afinal secundário, que não tem incidência nem a quer ter. Entenda-se que nem todas as composições podem ser etiquetadas como jogos literários, mas só poucas se podem adornar com o título de textos de conhecimento. Os líricos do século XIV andam por uma espécie de terra de ninguém: não aspiram àquele culto da forma que será censurado aos seus colegas do século XVI, mas nem tão pouco se aproximam daquele empenhamento ético que os detractores dos petrarquistas de Quinhentos hão-de reclamar. Relativamente ao passado imediato, acontece que a lírica, de instrumento maior da comunicação literária, se tornou um género, ou melhor, uma prática específica, um dos componentes, e nem sequer o mais importante, do sistema literário. Passam a ser outras as tipologias de escrita que veiculam conteúdos que interessam. A lírica continua a falar da realidade, individual e social, mas sob uma angulação parcial, desprovida de uma marca ideológica credível e com um tom que, no final de contas, não aspira a uma audição particularmente atenta.
As causas desse declínio são conhecidas: crise da instituição comunal, nascimento das "tiranias" e respectiva evolução para "senhorias", crescente papel desempenhado pelas novas cortes enquanto centros de produção de poesia de entretenimento e propaganda, transformação do poeta lírico, de "intelectual", em diletante ${ }^{17}$. Não foram os Stilnovistas, pois, que homologaram a rica variedade de propostas líricas da "geração do meio": as formas dessa lírica sobrevivem durante muito tempo. É o seu espírito que se vai apagando, pouco a pouco, e que se vai degradando, à medida que o século avança, em virtude do enfraquecimento daqueles pressupostos sociais, políticos e institucionais que lhe davam vida.

Nesse longo e confuso processo, de modo algum linear, dá-se um outro fenómeno bem conhecido, e que, porém, vale a pena sublinhar, ou seja, a ruptura da "linha gótica" por parte da lírica em toscano. O baricentro desloca-se da Itália central para a Itália setentrional, através de um arco geográfico compreendido entre Milão e Rimini: completa-se, assim, aquele movimento ascendente de Sul para Norte que caracterizou a história do primeiro século da poesia em vulgar. A partir desse período, os lances verdadeiramente decisivos, para a história do género, serão setentrionais. Se quisermos voltar a olhar as coisas de cima, para fazer o mapa do DNA da nossa lírica, não nos podemos contentar com a aposta na dupla Stilnovo - Petrarca: temos de recordar, pelo menos, os nomes de Giusto de' Conti di Valmontone e de Pietro Bembo. Inútil determo-nos sobre Bembo. Quanto a Giusto, é um dos elos imprescindíveis, não por ser romano, mas por ter morrido em Rimini. Acrescento,

17 Para um quadro de conjunto da poesia do século XIV, continua a ser insubstituível, Armando Balduino, Premesse ad una storia della poesia trecentesca, "Lettere italiane", XXV (1973), pp. 3-36, depois editado no vol. Boccaccio, Petrarca e altri poeti del Trecento, Firenze, Olschki 1984, pp. 13-55. 
um pouco provocatoriamente, que talvez não seja totalmente descabido considerar o próprio Petrarca um astro da galáxia setentrional.

4. Não acho que Petrarca alguma vez tenha imaginado que a lírica italiana de pelo menos dois séculos viesse a ser designada a partir do seu nome: nada, durante a sua vida, lho podia fazer crer. Se ter-se tornado mentor daquela tradição é culpa de alguém, Petrarca está seguramente inocente. Mas, dito isto, não é que não desempenhe um papel importante para o futuro desenvolvimento da poesia - e, poder-se-á acrescentar, de toda a literatura em vulgar -, mesmo em tempos que lhe são próximos, só que é um papel muito diferente do de pai fundador que lhe é legitimamente reconhecido. Um pouco a brincar, um pouco a sério, podíamos até dizer que Francesco Petrarca correu o risco de passar à história não como pai da lírica, mas como aquele que a sufocou ainda no berço. Teria tido cúmplices, com certeza, mas seu teria sido o plano do crime. Petrarca, de facto, é o supremo responsável por aquele relançamento da língua latina e do mundo clássico que foi o Humanismo, e o Humanismo produziu uma radical redistribuição das partes no sistema literário e cultural. O século que tinha começado com a Commedia, que a meio tinha visto nascer o Decameron e o Cancioneiro, isto é, que tinha sancionado a plena maturidade do vulgar, terminava com uma grande crise da literatura em vulgar. A partir das últimas décadas do século XIV, instaura-se, em Itália, um novo regime de bilinguismo, ou melhor, de duplo circuito: sem ser restrito, porém, a um género, como o tinha sido no século XIV, mas extensivo a qualquer manifestação da cultura escrita. A cultura 'alta' é perfeitamente latina, razão pela qual a literatura em vulgar decai, automaticamente, para um plano baixo. A lírica, então, que já tinha sofrido um processo de declínio no quadro dos géneros em vulgar, resvala para níveis baixíssimos.
As vicissitudes e o falhanço do "Certame coronario" de $1441^{18}$ são um bom teste para avaliar quão profunda era a crise do vulgar. Para evitar a derrota, Alberti tinha tomado todas as precauções: um assunto tipicamente clássico, a 'amizade', a obrigação, para os participantes, de introduzirem nas composições apresentadas a concurso sentenças tiradas dos clássicos. Por sua vez, tinha seleccionado composições que se diferenciavam das rimazitas correntes. Apesar disso, perdeu clamorosamente.

Não quer isso dizer que, no longo lapso de tempo que correu entre a morte de Petrarca e a consolidação, em pleno século XV, dos estados regionais, a produção lírica tivesse desaparecido; podemos dizer, bem pelo contrário, que foi mesmo naquele período, na área véneta e nas cortes dos Este, dos Malatesta e da área de Feltre, que se lançaram as sementes para o seu renascimento sob novas formas ${ }^{19}$. É, todavia, um dado de facto que essas décadas, consideradas globalmente, assinalam uma fractura na história da lírica. $\mathrm{Na}$ que virá depois, os elementos de novidade irão prevalecer sobre os de continuidade. "Nascer duas vezes", escrevi no título deste estudo, precisamente para sublinhar que a história da nossa tradição lírica, aparentemente unitária e linear, é, na realidade, bipartida. Uma duplicidade que até no tipo de competências dos estudiosos que dela se ocupam encontra correspondente: aos especialistas de lírica dos século XIII e XIV, pelo menos até Petrarca, são requeridas competências no âmbito da romanística, aos de lírica dos

${ }^{18}$ Reconstruídos em De vera amicizia. I testi del primo Certame coronario, ed. critica e commento a c. di Lucia Bertolini, Modena, Panini 1993.

${ }_{19}$ Pelo que respeita a este período histórico, remeto para o meu cap., "Fra Rimini e Urbino: i prodromi del petrarchismo cortigiano", in Marco Santagata, Stefano Carrai, La lirica di corte nell'Italia del Quattrocento, Milano, Angeli 1993, pp. 43-95, e para o livro de Italo Pantani, "La fonte d'ogni eloquenzia". Il canzoniere petrarchesco nella cultura poetica del Quattrocento ferrarese, Roma, Bulzoni 2002. 
séculos XV e XVI, competências no âmbito da poesia italiana e da poesia clássica.

A derrota de Alberti mostra que o resgate da poesia vulgar não se podia fazer a partir de dentro: não era de dentro da literatura, e muito menos de dentro da lírica, que podiam brotar os estímulos a um novo equilíbrio do quadro global dos géneros. A contraprova é dada pela circunstância de o relançamento, em grande estilo e com novas formas, da lírica vulgar ocorrer na segunda metade do século. É como dizer que só um novo quadro social e institucional podia baralhar as cartas e repor o equilíbrio das duas culturas.

Já delineei, noutra ocasião, os processos históricos que, do meu modo de ver, levaram ao extraordinário florescimento da lírica que desabrocha na segunda metade do século $\mathrm{XV}$, bem como os motivos pelos quais desponta com as cores de Petrarca ${ }^{20}$. Em poucas palavras: trata-se da consolidação do sistema das cortes, com a substituição, aos estados "tirânicos" ou senhoris da época precedente, não raro com uma dimensão municipal, de estados ou estadozinhos regionais, e da formação, dentro e em torno das cortes, de uma nova agregação social 'mista', aristocrática, mas não feudal, heterogénea e todavia coesa, homóloga na sua realidade, de corte para corte e de região para região, e, como tal, tendencialmente indiferente aos confins linguísticos e de tradição. Em suma, é esse conjunto de fenómenos políticos, institucionais e sociais a fecundar o terreno para um novo florescimento lírico. A lírica, ao retomar a dominante amorosa, reencontra uma função social que transcende o entretenimento e a propaganda, erigindo-se de novo em instrumento de agregação e em veículo de mensagens ideológicas. Com efeito, nas novas cortes ita-

${ }^{20}$ Remeto para o cap., "Dalla lirica 'cortese' alla lirica 'cortigiana': appunti per una storia”, no citado, Santagata, Carrai, La lirica di corte nell'Italia del Quattrocento, pp. 11-30. lianas acontece algo que se parece, ao longe, e sublinho ao longe, com o que tinha acontecido nas cortes feudais da Provença dos trovadores.

A grande peculiaridade da lírica italiana é precisamente essa, a de ter tido uma história quase ao invés da das outras tradições românicas. Aquilo que, noutras zonas da Europa, fica no início do processo, para nós verifica-se no fim. A Itália não conheceu uma verdadeira tradição lírica de cariz 'cortês': a nobreza feudal não teve força, nem vontade, para experimentar novas formas literárias, ficando colada à língua e às formas da Provença. A "burguesia" toscana procurou dar vida a uma produção lírica própria e recognoscível, numa tentativa original, porém de escassa duração. Foi então, em pleno século XV, que a lírica se tornou um dos ingredientes mais importantes da cultura de corte: não 'cortês', portanto, mas 'cortesão'. Uma nova figura social que, volvidas algumas décadas, assumirá o nome de 'gentil-homem', apropria-se desse ingrediente, elegendo-o como um dos seus traços distintivos. É assim que a Itália, que originariamente tinha vivido sobretudo de importação, se transforma em potência exportadora de lírica, a ponto de deter o monopólio europeu do género.

5. Género que assume a linguagem, as formas e o imaginário de Petrarca. Sabemos que o petrarquismo do século XV prescinde de uma teoria da imitatio e que consegue instaurar um código comum através da prática da imitação espontânea. Creio que esta conceptualização designa um fenómeno análogo ao da difusão das modas, na nossa época. Imitar um modelo porque o vizinho também o imita significa levar a cabo um acto de imitação para imitar um outro acto de imitação. Num processo em que imitação gera imitação, mais do que o modelo em si contam as modalidades da sua fruição. A sua soma, por entre semelhanças e diferenças, confere substância a uma tradição que não é alimentada do exterior, na medida em que se nutre a si própria. 
De outra forma, pode-se afirmar que não é o modelo a dar-lhe valor, sendo antes os actos de imitação que se seguem em cadeia a conferirem valor ao modelo. Com estas esquemáticas observações, pretendo sublinhar que, apesar de serem muitos e bem conhecidos os motivos que tornavam a poesia de Petrarca particularmente adequada para desempenhar aquele papel de referência, as verdadeiras razões em virtude das quais o Cancioneiro se elevou a modelo são externas ao livro. Tanto assim é que o reconhecimento oficial da sua autoridade modelizante há-de chegar mais tarde, quando já há muitos anos existe uma tradição petrarquista ou petrarquizante.

Para se poder difundir e vingar, a imitação por contágio deve encontrar um ambiente favorável, ou seja, um ambiente que induza cada pessoa a imitar o comportamento dos vizinhos. São vizinhos dos poetas líricos, não só e não tanto sob o ponto de vista espacial e geográfico, quanto por analogia de condição social e por homogeneidade ambiental, aqueles que estão sujeitos aos mesmos estímulos e são destinatários das mesmas solicitações. Estamos a falar do ambiente de corte. Não é com certeza por acaso que a distribuição geográfica dos poetas que petrarquizam, nos últimos quarenta anos do século, coincide quase perfeitamente com a das cortes. Bastará lançar um olhar sobre a carta política da Península para ver como, no declínio do século, depois do regresso em força da poesia à Itália meridional, foi levada à perfeição uma espécie de cerco àquela Toscana não cortês e, por isso, petrarquística de modo anómalo.

Nos anos cinquenta e sessenta do século XX, quando foi retomado esse género de estudos depois do eclipse idealista, para individuar a peculiaridade do petrarquismo quatrocentista elaborou-se a categoria de petrarquismo apetrarquesco ou de petrarquismo sem Petrarca. Era uma forma de sublinhar, conforme escrevia Maria Corti, que "nel Quattrocento il Petrarca non è che una delle componenti del petrar- chismo" 21 . Essa ideia, bastante útil para livrar a poesia petrarquista do século XV da hipoteca quinhentista, por sua vez etiquetada como expressão de um petrarquismo "hortodoxo" ou "integral" 22 , apesar de continuar a sobreviver em histórias da literatura e manuais, parece-me que já teve os seus dias. Germinada no seio das pesquisas dos historiadores da língua, que por aquelas décadas detinham uma espécie de monopólio do estudo da literatura em vulgar do século XV, exprimia um ponto de vista parcial. Hoje, porém, o nosso conhecimento do petrarquismo quatrocentista não é comparável com o que então se detinha. O que é mais, elaborámos uma visão panorâmica do petrarquismo que engloba petrarquismos individualizados, tendo a possibilidade de valorizar, como tal, aqueles aspectos propriamente literários, esmagados pelas interpretações centradas sobre a língua.

Dizia anteriormente que a lírica cortesã do século XV se parece, ao longe, com a lírica cortês trovadoresca. Pensava na dimensão social de ambos os fenómenos, na sua função modelizante de comportamentos e costumes, na sua capacidade de criar um vocabulário comum a todo um estrato social. Não pretendia, porém, minimizar a substancial diferença entre as duas tradições.

À primeira vista, a lírica cortesã podia parecer comprometida com a vida social e de relação, mais ainda do que a lírica cortês. Acontecimentos do quotidiano, pequenas ou grandes ocasiões da história, festas e encontros mundanos, testemunhos e garantias da autenticidade do narrado povoam as composições dos líricos cortesãos. No entanto, e é esta a nítida

${ }^{21}$ Pietro Jacopo De Jennaro, Rime e lettere, a c. di Maria Corti, Bologna, Commissione per i testi di lingua 1956; cit. p. XLVI. Quem escreve utilizou amplamente conceitos como esses na obra, La lirica aragonese. Studi sulla poesia napoletana del secondo Quattrocento, Padova, Antenore 1979.

22 São definições de Emilio Bigi, Lorenzo lirico, in Dal Petrarca a Leopardi, Milano-Napoli, Ricciardi 1954, pp. 23-45. 
diferença entre corteses e cortesãos, os textos líricos do século XV não são parte integrante dos rituais de corte ou de sociedade: não são concebidos nem a pensar numa performance, nem com aquelas intenções pragmáticas (pedidos, favores, relações privilegiadas) próprias de muitas composições trovadorescas. Os líricos que petrarquizam 'espelham' um ambiente social, dele fazendo parte, porém, enquanto cortesãos e gentis-homens, não enquanto poetas. Entre a sociedade de que falam e a sua poesia, um diafragma permanece. $O$ desfasamento entre representado e representação define a sua operação como acto eminentemente literário.

A principal característica do petrarquismo cortesão, que é a que o distingue da precedente tradição lírica e, pelo menos em parte, como veremos, da quinhentista, é o facto de se manifestar através de livros de rimas de autores individualizados. A poesia lírico-amorosa de marca petrarquista configura-se, ao longo desse período, como um sistema de homens e de livros e, portanto, de individualidades. Mesmo em presença de um vocabulário comum, de práticas largamente partilhadas e de um universo discursivo tendente à homologação, permanecem inalteradas a função-autor e a função-obra. Talvez se pudesse ser mais claro e dizer que a função-autor e a função-obra se afirmam, a partir do momento em que, se não por outras razões, em termos quantitativos, correspondem a uma novidade relativamente à época passada, na qual anonimato e dispersão eram características importantes do género lírico. Tanto mais assim é, andando obras e autores estreitamente ligados: muitas vezes o poeta cortesão pratica somente o género lírico, sendo quase sempre autor de um único livro de rimas, o livro de uma vida.

Evitei deliberadamente utilizar a palavra cancioneiro. Nem sempre, poder-se-ia até dizer, raramente, os livros de rimas do século XV são modelados a partir de Petrarca. Bordejam só as suas margens mais evidentes e externas. Todavia, não são recolhas organizadas por géneros métricos ou por temas, segundo critérios extrínsecos. Tendem a estruturar-se ao longo de um fio lógico, narrativo ou sentimental. Afinal de contas, o que interessa é que se trata de "livros de autor": um livro de rimas, quaisquer que sejam as suas premissas, reenvia automaticamente para Petrarca, porque o livro foi a grande inovação (desprovida de sequazes, contudo, durante muito tempo) que introduziu na história do género. Sob este ponto de vista, os líricos cortesãos, que sob outros aspectos se mostram muito livres em relação ao modelo, são considerados petrarquistas a pleno título. À sua maneira, naturalmente: um modo arriscado porquanto, no fundo, contraditório. Pretendem comprimir dentro das estruturas fechadas de um livro, podendo até conferir-lhe um andamento narrativo, uma produção aberta, vária, descontínua, socializada, e portanto de marca não petrarquesca. Todavia, o predomínio da instância literária impede que esta lírica se acomode à função de mera modalidade comunicativa, de acto efémero e extemporâneo. Também a consciência de estar a fazer literatura remete para Petrarca.

6. Na segunda metade do século XV, a imitação por contágio deu vida a uma tradição ampla e, sobretudo, recognoscível. Se não tivesse havido esse petrarquismo de facto, teria sido impensável a existência do próprio petrarquismo regular, teorizado e sustido, no século XVI, por instrumentos de trabalho apropriados.

A mais relevante herança que os líricos do século XV deixam ao nascente mercado editorial é, muito provavelmente, o livro de rimas. Não é fácil desbravar, com meia dúzia de frases, o grande mar da produção de rimas impressas: vou avançar, como se costuma dizer, a corta-mato.

$\mathrm{Na}$ idade dos incunábulos, os cancioneiros, ou melhor, os livros de autor são uma minoria ${ }^{23}$. É significativo, porém,

${ }^{23}$ Fundamento-me nas pesquisas de Nadia Cannata, Il canzoniere a stampa (1470-1530). Tradizione e fortuna di un genere fra storia del libro e letteratura, Roma, 
que quase todos provenham de círculos de corte: Milão, Mântua, Ferrara, Urbino, Nápoles. Nas primeiras três décadas do século XVI, o número de livros impressos de um só autor conhece um forte incremento, tanto que ultrapassa, à vontade, o das colectâneas de vários autores. A confirmar a centralidade do livro de autor, para além dos meros dados quantitativos, há também a considerar uma nítida tendência, por parte das tipografias, para conferirem uma forma unitária ao produto lírico de finais do século $\mathrm{XV}$, o qual dela era originariamente desprovido. No ponto culminante de um processo inaugurado com a edição de Petrarca feita por Aldo Manuzio em 1501, coloca-se a publicação, em 1530, das rimas de Bembo e de Sannazaro. Por essa data, o caminho rasgado com a fixação que Manuzio fizera do modelo tipográfico do livro de rimas parecia ter atingido a sua meta: o petrarquismo encontrou uma teoria que regulava o plano linguístico-expressivo e uma forma privilegiada, o livro unitário, meio de transmissão estabilizado. Assim nasce, como nos ensinou Dionisotti ${ }^{24}$, o petrarquismo do século XVI. E contudo, se de um ponto de vista centrado na observação do livro impresso lançarmos um olhar para o que sucederá nas décadas sucessivas, aquilo que foi indicado como sendo um início pode mesmo parecer um fim.

No século XVI, a noção de cancioneiro é bastante problemática ${ }^{25}$, tão problemática que o próprio modelo petrarquesco pode ser submetido a leituras drásticas, ou até res-

Bagatto Libri 2000; de grande valor é o repertório de livros de poesia reunido por Italo Pantani: Biblia. Biblioteca del libro italiano antico, diretta da Amedeo Quondam; La biblioteca volgare, 1 Libri di poesia, a c. di Italo Pantani, Milano, Editrice bibliografica 1996

${ }^{24}$ Carlo Dionisotti, Appunti sulle rime del Sannazaro, "Giornale storico della letteratura italiana", 140 (1963), pp. 161-211.

25 Também o notou Guglielmo Gorni, Le forme primarie del testo poetico, in Letteratura italiana, diretta da Alberto Asor Rosa, III Le forme del testo, 1, Teoria e poesia, Torino, Einaudi 1984, pp. 439-518 (para o cancioneiro, cf. pp. 504-18). truturado (como o fez Vellutello na edição de 1525, o mesmo ano, note-se bem, das Prose de Bembo), a ponto de aniquilar a sua configuração originária ${ }^{26}$. No plano da prática poética, abundam sinais da crise daquela forma: desde o grande número de inéditos ou de edições póstumas que parece ser uma característica dos livros de autor mais estruturados, até à grande liberdade tida na construção dos cancioneiros, na medida em que as preocupações de adesão a um arquétipo são muito menores de quanto o haviam sido, e já com bastante liberdade, no século anterior. O que mais interessa, numa perspectiva de história da literatura, é que num século XVI maduro, problemática não seja apenas a noção de cancioneiro, mas também a de livro de autor, apesar de ter uma estrutura. $\mathrm{Na}$ difusão de textos líricos através da imprensa, as antologias de vários autores assumem, de facto, um papel que tende a aumentar de peso com a passagem do tempo, e que se vai fazendo mais relevante, sem dúvida, do que o dos livros de autor. Não é excessivo afirmar que essa tipologia se torna constitutiva da própria prática lírica, a ponto de definir a sua natureza e a sua função ${ }^{27}$. Quero dizer que, se a lírica de corte do século XV se apresenta como uma sociedade de indivíduos e de livros, a de um século XVI maduro surge como uma galáxia de microtextos.

A primeira impressão é a de que este nosso percurso nos tenha conduzido através de uma paisagem bem conhecida: a difusão de textos soltos ou de miscelâneas de vários auto-

${ }^{26}$ Quanto a Alessandro Vellutello, pode-se ver o capítulo que lhe foi dedicado por Gino Belloni, Laura tra Petrarca e Bembo. Studi sul commento umanistico-rinascimentale al "Canzoniere", Padova, Antenore 1992.

27 Precursor deste tipo de estudos foi Amedeo Quondam, Petrarchismo mediato. Per una critica della forma "antologia", Roma, Bulzoni 1974. Sobre o século XVI, veja-se também o volume, "I più vaghi e i più soavi fiori”. Studi sulle antologie di lirica del Cinquecento, a c. di Monica Bianco ed Elena Strada, Alessandria, Edizioni dell'Orso 2001. 
res não terá sido, talvez, o modo originário e, sobretudo, duradouro e prevalecente, através do qual a poesia lírica chegou ao seu público? Se assim fosse, o período dos livros de rimas, ou seja, os sessenta anos aproximadamente compreendidos entre 1470 e 1530, não seria senão um parênteses, ou até um desvio, num percurso substancialmente homogéneo. Mas a primeira impressão é enganadora. Não que os líricos 'cortesãos', que um consolidado topos historiográfico vê substancialmente como um grupo de poetas bizarros e extravagantes, devam ser desprovidos da aura quase preclassicista que me esforço em lhes conferir (isso não), permanecendo contudo os únicos que tentaram impor um género literário semelhante ao inventado por Petrarca no Cancioneiro: é que os líricos quinhentistas não podem ser assimilados aos colegas dos séculos precedentes. A imprensa, na verdade, modificou profundamente a função e, como tal, as características dos seus produtos. A lírica, que ao longo dos tempos veiculou instâncias e representou modos de ser de nobres feudais, de burgueses de comunas e cidades, de gentis-homens de corte, em pleno século XVI parece não possuir um referente social definido: não fala uma linguagem comum de classe, exprimindo antes experiências e pensamentos de pessoas singulares ou, no máximo, de pequenos grupos. Em compensação, porém, ao dirigir-se ao público anónimo e indiferenciado do mercado, tem um auditório como nunca o tivera a anterior lírica, seja pelo que diz respeito à composição social dos leitores, seja pelo que diz respeito à quantidade do seu número. Dito em termos extremamente sintéticos, talvez seja a primeira vez (à parte Petrarca, bem entendido) que o "eu" lírico não se deixa tão facilmente traduzir por um "nós" e, sobretudo, que àquele "eu" não correspondam um "tu" ou um "vós" com uma fisionomia reconhecível. Apesar de ser o primeiro fenómeno de literatura de massas da nossa história, o petrarquismo quinhentista resiste à análise sociológica.
Também em virtude de outros motivos de fundo a impressão de déjà vu é errada. É certo que a fragmentação, a variedade, a multiplicação de angulações e pontos de vista e a função difusamente comunicativa assumida pelos textos líricos, que não é menos importante (ou seja, o facto de serem, em muitos casos, referenciais, andando associados a práticas de sociedade, podendo ter por fulcro as mais variadas finalidades pragmáticas), é certo que tudo isso não produz uma sensação de desordem, e muito menos de caos. Pelo contrário, esse complexo dotado de inúmeras facetas apresenta-se como um conjunto compacto, homogéneo, sistemático. A garantir a resistência de um género que continha em si todas as condições para se desagregar ainda mais desastrosamente de quanto se tinha desagregado no século XIV, está a força modelizante do classicismo nas suas várias declinações: forma mentis, teoria da imitatio, prática poética fundada em mecanismos de réplica e repetição ${ }^{28}$. A prática e a teoria classicistas erigem Petrarca na própria condição de existência de uma produção lírica que, na concepção e na prática, é o que mais longe dele se possa imaginar.

Afirmei anteriormente que é tempo de remeter para a história dos nossos estudos a categoria de "petrarquismo sem Petrarca". Entendo que há uma outra categoria interpretativa que continua a gozar, por sinal, de um certo crédito, que também deve ser abandonada: refiro-me à ideia, que subjaz à noção de petrarquismo integral, segundo a qual os líricos do século XVI teriam associado uma imitatio stili e uma imitatio vitae: Petrarca mestre de estilo e de vida ${ }^{29}$. Não me parece, de facto, que nos textos (nos textos líricos, quero

28 Acerca destes temas, não pode deixar de ser feita remissão para os trabalhos de Amedeo Quondam, com relevo para o livro, Il naso di Laura. Lingua e poesia lirica nella tradizione del Classicismo, Modena, Panini 1991.

29 A ideia foi sobretudo difundida através do tão conhecido livro de Luigi Baldacci, Il petrarchismo italiano nel Cinquecento, Padova, Liviana 1974 (2 ed.; a primeira remonta a 1957). 
dizer, e não em tratados ou comentários) se encontrem exemplos significativos de uma tal abordagem. A ideia de que os poetas petrarquistas o seguem como modelo das suas vicissitudes espirituais, na parábola entre amor e arrependimento, não encontra correspondente nos seus versos. Não é esse o Petrarca que encontramos nos cancioneiros quinhentistas, nem é isso o que caracteriza, primordialmente, o grande fenómeno petrarquista desse século.

7. Uma última observação. Um universo lírico imitativo e repetitivo como este, tanto mais que se estende assim pelo tempo, com uma tamanha riqueza de textos, a nós, leitores posromânticos, pode provocar, como ensina De Sanctis, uma sensação de artificiosidade e de inutilidade ou, pior ainda, de aborrecimento e asfixia. Mas a nós, historiadores do fenómeno literário, oferece valiosa e abundante matéria de reflexão. Sob risco de poder parecer paradoxal, convido a considerar o facto de o classicismo quinhentista, precisamente em virtude das regras que lhe permitiam conservar unidos, sob a égide de um único código, actos singulares vários e diferenciados, ter sido também, a longo prazo, um factor de libertação. Bem o podemos verificar, se acompanharmos a evolução dos livros de rimas no Maneirismo e, depois, no século XVII. A forma da antologia de vários autores e a da recolha de rimas de um único autor, internamente articulada em subgéneros temáticos, foram, sob o ponto de vista histórico, as incubadoras de um processo que levou a lírica a libertar-se, primeiro, da hipoteca petrarquesca e depois das próprias regras de género a que obedecia. Através desses livros, a lírica começou, de facto, a diferenciar-se no seu espaço interno, a especializar-se, a enveredar por vias centrífugas. À força de tanto acumular recolhas especializadas e parciais, de sublinhar peculiaridades discursivas e agregações temáticas, a lírica acabará por perder a sua unidade de superficie e, por fim, a própria consciência de género em si. De género literário que desde as origens se tinha carac- terizado como género que englobava e reduzia à unidade o diverso, no século XVII e, sobretudo, no XVIII, transformar-se-á em género do qual se separam, gradualmente, diversas modalidades poéticas que acabarão depois por encontrar uma codificação autónoma. Quando um grande poeta sentir de novo a exigência de organizar os seus poemas em forma de livro, deixará de ter um modelo ou uma tradição a que se deverá adequar ou de que se deverá distanciar: há-de encontrar no interior desse espaço as razões que fazem de uma recolha de poesias um livro. Assim hão-se nascer os Canti de Leopardi que, paradoxalmente, até se poderão apresentar como uma derradeira homenagem àquele Cancioneiro então longínquo, finalmente restituído à sua unicidade irrepetível. 